\title{
MODELING OF THE SPONTANEOUS POLYPROPYLENE SORBENTS IMBIBITION WITH EMULSIONS
}

\author{
Jerzy SĘK, Olga S. SHTYKA, Kamila SZYMCZAK \\ Department of Chemical Engineering, Faculty of Process and Environmental Engineering, \\ Lodz University of Technology, Wolczanska St. 213, 90-924 Lodz, Poland
}

Submitted 06 Nov. 2013; accepted 01 Sept. 2014

\begin{abstract}
Oil penetration into aqueous media results in various chemical and physical processes including formation of "oil-in-water" emulsions, that have devastating effects on the environment. This research was conducted to evaluate the kinetics of permeation of "oil-in-water" emulsions into synthetic porous material. It gives the ability to develop more effective sorbents, decreasing risks of negative consequences and environmental contamination. The following publication focuses on assessment of the possibility to describe and predict a process of porous medium imbibition with emulsions by means of the Hill equation. Its adequacy is compared with the classical Lucas-Washburn equation and its modified version. The advanced approach is to substitute the commonly used parameter of the height of an imbibed emulsion $(h(t))$ by the parameter $m_{h}(t)$, which is the mass of an imbibed emulsion in the case of the classical and modified Washburn equations. According to the obtained results, the Hill equation provides the most appropriate and precise description of the porous material imbibition with "oil-in-water" emulsions and oil in comparison with others, and shows the highest correlation values $\left(R_{a v}=0.995 \pm 0.001\right)$ and the lowest normalized root mean square error (NRMSE $\left.E_{a v} 1.95 \pm 0.138\right)$.
\end{abstract}

Keywords: oil spill, emulsion, imbibition, porous material, Hill equation, classical Lucas-Washburn equation, modified Washburn equation.

\section{Introduction}

During the last several decades, the problem of environmental contamination with oil products has become one of the most serious global issues (Fingas 2011). The majority of oil and its derivatives is discharged into the aquatic ecosystems as a result of accidental spillings from tankers and underwater pipelines, emergency leakages during oil drilling process and surface runoff from land-based sources (Schnoor 2010; Fingas 2011; Valentukevičiené, Ignatavičius 2011). As a result of oil spillings in the aqueous medium, chemical and physical processes occur. Evidently, an emulsification process is considered to be constitutive due to its significant influence on the characteristics of organic contaminantion over time. The process of emulsification facilitates increase in density and corresponding viscosity (Wei et al. 2003). To this point, an oil emulsion is indicated as a microheterogeneous system consisting of two practically non-intersoluble liquids that differ in molecula nature (e.g. water is polar and another is non polar or low-polarity organic liquid). There are a lot of specific factors intensifying a process of "thin-layer oil" emulsification, but the dominant ones are as follows: action of the inertia force of mixing, waves and wind influence, turbulence of a stream, etc. In the open aquatic environment rapid surface spreading of the spilled oil occurs. Moreover, this process additionally stimulates and provides increase in emulsification rate (Wei et al. 2003; Al-Majed et al. 2012).

Obviously, the oil-spill-derived hydrocarbons in water ecosystems pose an extremely high risk to the environment due to general toxicity for the aquatic and terrestrial biota (Onwurah et al. 2007). The contaminants interrupt the food chain and without exception cause deterioration of water quality, e.g. depletion of the dissolved oxygen content due to increase in biochemical oxygen demand (BOD) for the organic components transformation into inorganic species (Shafir et al. 2007). Subsequently, the recovery of the spilled oil and derived hydrocarbons is considered to be the actual point at issue. Mechanical removal of spilled oil products by application of sorbents is

Corresponding author: Olga S. Shtyka

E-mail: olga.shtyka@gmail.com 
regarded as the most effective method. The main principle consists of concentration of the liquid oil-spill-derived hydrocarbons in solid material commonly known as a sorbent (Adebajo et al. 2003; Al-Majed et al. 2012).

The suggested remediation approach is based on the physical phenomenon known as capillary rise. The process of material filling with a liquid can be called absorption if it occurs mostly due to the capillary suction pressure or external pressure (Masoodi et al. 2007). If a fluid in the porous medium is replaced by a more viscous one, this phenomenon is called imbibition (Alava et al. 2004). In the scientific literature, the research related to the process of liquid penetration into the porous medium and its kinetics are acute issues for discussion as well as its mathematical describing and modeling.

The equation proposed firstly by Lucas and Washburn is considered to be a basis for description of liquid rise in a capillary. However the model has some limitations, e.g. the impacts of gravitational and inertial forces are neglected (Zhmud et al. 2000; Fries, Dreyer 2008; Maggi, AlonsoMarroquin 2012). Recently, there has been a continuing interest in this sphere due to the fact that many phenomena are based on capillary rise. It explains that there has been a great deal of efforts to describe this process, mostly grounded on the classical and modified Lucas-Washburn equations (Zhmud et al. 2000; Siebold et al. 2000; Hamraoui, Nylander 2002; Xue et al. 2006; Fries, Dreyer 2008; Maggi, Alonso-Marroquin 2012).

Zhmud et al. in their research work pay special attention to the capillary rise of surface-active substances. Thus, the peculiarities of surfactant transport in the porous medium are reviewed as well as relaxation processes in the adsorption layer. The asymptotic solutions corresponding to both short and long time limits were also drawn in the referred publication (Zhmud et al. 2000). The influence of dynamic contact angle on the capillary rise of total wetting liquids was investigated in the work of Siebold et al. in 2000. It is worth noticing that the experiments were carried out both in a single glass capillary and in a column packed with powders (Siebold et al. 2000).

Hamraoui and Nylander investigated mechanisms regulating the dynamics of the capillary rise in the view of dissipation channels (Hamraoui, Nylander 2002). Factors affecting the significance of gravity within the process of fluid penetration into a porous medium are analyzed in another publication (Chan et al. 2004). The hydrostatic effect of the spontaneous dynamic capillary rise is a subject of discussion in the research work of Xue et al. The equation relevant to spontaneous capillary rise that expresses correlation between time and height of a liquid front and takes into consideration the hydrostatic effects was proposed by Xue et al. in 2006. The dynamics of liquid penetration into a capillary tube in the case of small inertial effects is a field of Chebbi's researches. The important issues analyzed in this publication are: effect of the contact line speed on the dynamic contact angle and gravity influence on a fluid penetration into a vertical tube (Chebbi 2007). The investigations of Fries, Dreyer connect with deriving the analytic solution for capillary rise in a cylindrical column and in a porous material. A modified form of the classical Lucas-Washburn equation is proposed which takes into consideration the gravity term as a hydrostatic pressure. It provides the possibility to define behavior of the fluid rise in porous medium during the long-term period (Fries, Dreyer 2008).

The derived analytical solutions for gas displacement by a liquid in horizontal and inclined capillary tubes are represented in Hilpert's research work. Proposed solutions permit definition of various flow scenarios for a process of a liquid withdrawal from a capillary tube depending on flow direction and acceleration of the gas-liquid interface (Hilpert 2010). In a recent paper, a model of the meniscus movement in capillaries that accounts for the effect of a gas phase is described. The gas-related effects are proved to be important in the same way as the inertia and reservoir effects (Maggi et al. 2012).

This work focuses on assessment of the Hill equation's ability to predict the process of spontaneous imbibition of a porous material with "oil-in-water" emulsions and to compare its adequacy with both the classical and modified Washburn equation. In the present paper, the mentioned equations are also modified due to applying the parameter of an imbibed mass as a function of time instead of describing the relation between time and a fluid height.

\section{General characteristics of materials and experimental media}

In practice, synthetic sorbents are made on the basis of high molecular weight polymers, mainly from polyurethane, polyethylene and polyamides fibers (Zhu et al. 2011). In the current experiments the polypropylene fiber "Polfilter" of regional production (obtained from "Zakład Pracy Chronionej”, Lodz) was used as a synthetic sorbent of emulsions.

The oil-based liquid employed in the research was kerosene oil "Dragon" that is produced by "Zakład Chemii Budowlanej” (Kampinos, Poland). Its emulsions with different concentrations of the dispersed phase were applied as the investigated medium.

The edible gelatin "Delecta" from JSC "Rieber Foods Polska" was used as an additive to increase the viscosity of the obtained emulsions. The surfactant "Rokacet" (Chemical Plant "Rokita", Brzeg Dolny) served as an emulsifier to reduce the interfacial tension between the phases in the prepared media due to its partial solubility in both emulsion phases. The coloring agent was "Sudan III" added to the 
emulsions to facilitate observation of the imbibition process.

Thus, the experimental media were emulsions prepared by means of kerosene oil mixing with water, having dispersed phase concentrations (DPC) of $0.5 \% ; 1 \% ; 10 \%$ and $20 \%$. The concentration of the surfactant was $2 \%$ and fractions of gelatin (GC) consequently were as follows: $0.05 \%$ and $0.1 \%$.

In the present experimental work viscosity and density of emulsions were measured and results are represented in Table 1.

Table 1. Properties of the prepared "oil-in-water" emulsions

\begin{tabular}{lcccc}
\hline \multirow{2}{*}{ Property } & \multicolumn{4}{c}{$\begin{array}{c}\text { Concentration of the dispersed phase } \\
\text { in the investigated emulsion }\end{array}$} \\
\cline { 2 - 5 } & $0.5 \%$ & $1 \%$ & $10 \%$ & $20 \%$ \\
\hline $\begin{array}{l}\text { Density, } \\
\mathrm{kg} / \mathrm{m}^{3}\end{array}$ & 999 & 998 & 980 & 960 \\
\hline \multicolumn{5}{c}{ concentration of gelatin $0.05 \%$} \\
Viscosity, & 0.925 & 0.893 & 0.923 & 0.925 \\
\cline { 2 - 4 } \begin{tabular}{l} 
mPas \\
\cline { 2 - 4 }
\end{tabular} & \multicolumn{4}{c}{ concentration of gelatin $0.1 \%$} \\
\hline
\end{tabular}

\section{Experimental procedures}

The imbibition capacity of the polypropylene sorbent was determined directly by dipping the material sample into the prepared emulsion. In previous scientific research concerning the capillary rise of liquids, a glass tube and/or a column packed with sorbent was used (Zhmud et al. 2000; Siebold et al. 2000; Fries, Dreyer 2008). In the current experiment a strip was used in order to investigate entirely the imbibition capacity of the offered media.

A strip of the polypropylene sorbent of width of $3 \mathrm{~cm}$, length of $20 \mathrm{~cm}$, and thickness of $0.5 \mathrm{~cm}$ was submerged with one end into the emulsion to a depth of $2 \mathrm{~cm}$ (see Fig. 1).

The process of imbibition was followed from the moment the polypropylene material was put in contact with the medium. The main consideration was description of the kinetics of the mass change of an imbibed emulsion, $m_{h}(t)$ in the determined period of time, $(t)$. The mass difference between the initial mass of an emulsion in a beaker (see (3) in Fig. 1) and the mass after sorbent immersing was accepted as the mass of imbibed liquid.

Measurements were taken until steady state was reseved. The measurement of an imbibed mass was observed at $15 \mathrm{sec}, 30 \mathrm{sec}$, and $1 \mathrm{~min}$ after the process beginning.

\section{Modeling of the process of sorbent imbibition with emulsions}

The process of imbibition is based generally on capillary rise, thus the Washburn equation describing this process

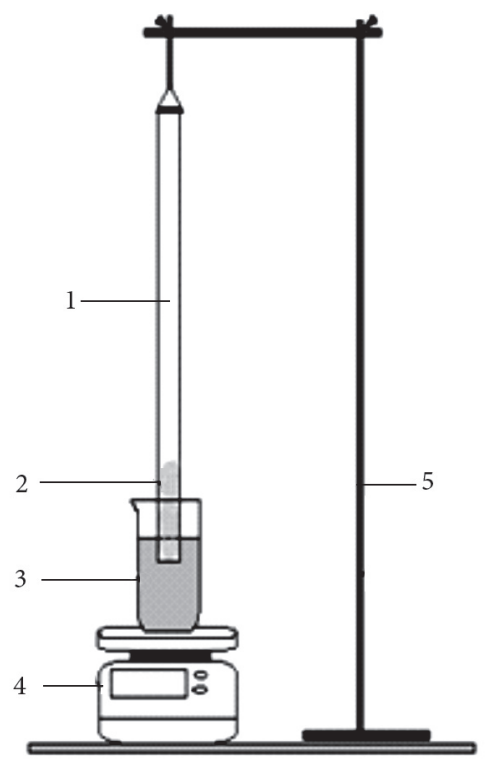

Fig. 1. Scheme of the device used to measure imbibition capacity: 1 - polypropylene stripe; 2 - imbibed emulsion; 3 - beaker with the investigated emulsion; 4 - analytical balance; 5 - stand

can also serve for analyzing issues concerning the spontaneous imbibition of porous medium with an emulsion (Zhmud et al. 2000; Fries, Dreyer 2008; Maggi, AlonsoMarroquin 2012). The previously mentioned basic equation is occasionally known as the Lucas-Washburn equation. In this case, it has the following form:

$$
t=a_{1}\left(b_{1}\left(\ln \left(\frac{b_{1}}{b_{1}-h(t)}\right)\right)-h(t)\right),
$$

where $h$ is the height of an imbibed emulsion; $t$ is the time of the process duration; $a_{1}, b_{1}$ are parameters of the given equation.

The height of an imbibed emulsion $(h(t))$ in Eq. 1 was replaced by the parameter $m_{h}(t)$, the mass of an imbibed emulsion, consequently after substitution the equation can be represented as follows:

$$
t=a_{1}\left(b_{1}\left(\ln \left(\frac{b_{1}}{b_{1}-m_{h}(t)}\right)\right)-m_{h}(t)\right),
$$

where $m_{h}$ is the mass of an imbibed emulsion; $t$ is the time of the process duration; $a_{1}, b_{1}$ are parameters of the equation.

Although the equation is proven as valid in a majority of cases, it can become inadequate due to various contradictions with the fundamental laws of hydrodynamics (Zhmud et al. 2000; Fries, Dreyer 2008). Moreover it is impossible to describe correctly the process of the capillary rise in a porous medium on account of the parameters selectivity. It takes into account viscosity, interfacial tension, and boundary pressure (Maggi, AlonsoMarroquin 2012). 
Taking into consideration criticisms of the classical Washburn equation, there are many attempts to describe the capillary rise by means of modifications of this widely used equation (Zhmud et al. 2000; Fries, Dreyer 2008). For example, Fries, Dreyer proposed a modified version of the classical Washburn equation to describe the capillary rise of surfactant and to obtain more accurate solutions (see Eq. 3).

Therefore the modified equation may be expressed as follows:

$$
h(t)=\frac{a_{2}}{b_{2}}\left(1-e^{-\frac{t b_{2}^{2}}{a_{2}}}\right),
$$

where $h$ is the height of an imbibed emulsion; $t$ is the time of the process duration; $a_{2}, b_{2}$ are parameters of the given equation. The proposed expression is considered to be an equation that evolves long time asymptotic solution (Fries, Dreyer 2008).

In Eq. 3 the height of an imbibed emulsion $(h(t))$ was also substituted by the parameter $m_{h}(t)$, the mass of an imbibed emulsion, and finally after rearranging one obtains:

$$
m_{h}(t)=\frac{a_{2}}{b_{2}}\left(1-e^{-\frac{t b_{2}^{2}}{a_{2}}}\right),
$$

where $m_{h}$ is the imbibed mass of an emulsion; $t$ is the time of the process; $a_{2}, b_{2}$ are parameters of this equation.

Additionally, the Hill equation was applied to describe the imbibition process. It is recognized primarily for modeling of biochemical processes in physiological and pharmacological investigations and was derived from the law of mass action (Gesztelyi et al. 2012). The Hill equation is mainly used to analyze the binding equilibrium in ligand-receptor interactions (Goutelle et al. 2008), but its classical form (Gesztelyi et al. 2012) was found as appropriate to describe the process of porous material imbibition with various emulsions. Eventually including some alterations, the classical form of the Hill equation can be rewritten as:

$$
m_{h}(t)=V_{\max } \frac{t^{n}}{k^{n}+t^{n}},
$$

where $m_{h}$ is the imbibed mass of an emulsion; $t$ is the time of the process duration; $V_{\max }, k, n$ are defined as parameters of the proposed equation.

The accuracy of the models was estimated via correlation coefficient, $R$ (see Eq. 6) and normalized root mean square error, NRMSE (see Eq. 7) in accordance with following formulas:

$$
\begin{gathered}
R=\frac{\operatorname{cov}(x, y)}{\sigma_{x} \sigma_{y}}=\frac{\sum\left(x_{i}-\bar{x}\right)\left(y_{i}-\bar{y}\right)}{\sqrt{\sum\left(x_{i}-\bar{x}\right)^{2} \sum\left(y_{i}-\bar{y}\right)^{2}}}, \\
N R M S E=\frac{\sqrt{\frac{1}{n} \sum_{i=1}^{n}\left(x_{i}-y_{i}\right)^{2}}}{y_{\max }-y_{\min }},
\end{gathered}
$$

where $x_{i}$ is the calculated data; $y_{i}$ is the experimental data; $\bar{x}$ and $\bar{y}$ are the mean values of data and $\mathrm{n}$ is the number of experiments (Gmurman 2004).

The Origin Program which applies the LevenbergMarquardt algorithm (LMA) was used for the experimental data approximation by means of the proposed mathematical models.

\section{Analysis of results and discussion}

The experimental data obtained for the process of polypropylene material imbibition with emulsions during a defined time period were fitted using previously mentioned equations (see Eq. 2, Eq. 4 and Eq. 5).

According to analysis of the results, changes in the character of the process of the material imbibition with time were noticed. Thus, when correlation between a mass of an imbibed emulsion and a maximal mass $\left(m_{i m} / m_{\max }\right)$ gets near $0.3(\sim 0.00682 \pm 0.00026 \mathrm{~kg})$, the rate of the imbibition decreases in all investigated cases. It provides the possibility to divide imbibition process into two phases. The first is characterized with a fast rate that is supposed to be conditioned by inertial forces, whereas within the second stage the process slows down and transfers into a so-called viscous phase (Siebold et al. 2000). The rapid reduction of the imbibition kinetics is defined as a transition point (Siebold et al. 2000). The time interval after the moment of transition is also accompanied with a change of the equations parameters used for fitting. Correspondingly, in this publication two phases of the process of the porous material imbibition were investigated, though the entire imbibition process was also considered and analyzed as an additional case.

The values of the equations coefficients used for fitting are given in Tables 2-4.

For the classical Washburn equation, it is difficult to see a trend with regard to coefficients $a$, and $b$. Thus, the parameter $a$ lies in the scattered range from 0.241 to 14.071 and correspondingly the parameter $b$ varies from 0.150 to 8.329 without determined regularities in their distribution (see Table 2).

The values of the coefficients for the modified Washburn equation are represented in Table 3. It is possible to deduce a probable tendency of the coefficients alteration within the second phase of the investigated process. Thus, values of the parameters increase uniformly with increase in the dispersed phase concentration in emulsions. This tendency is defined as typical for emulsions with the different concentrations of gelatin. On condition that concentrations of the oil phase are relatively low, e.g. $0.05 \%$ and $1 \%$, the parameter $a$ is close to $2.867 \pm 0.027$ and $b$ is $2.647 \pm 0.045$. For emulsions with dispersed phase concentration of $10 \%$ and gelatin concentration of $0.05 \%$, the values of $a$ and $b$ are higher and equal to $3.772 \pm 0.049$ and 
Table 2. Parameters for the classic Lucas-Washburn equation

\begin{tabular}{|c|c|c|c|c|c|}
\hline \multirow{2}{*}{ 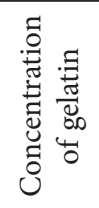 } & \multirow{2}{*}{ 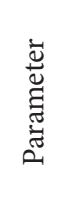 } & \multicolumn{4}{|c|}{$\begin{array}{c}\text { Concentration of the dispersed phase in } \\
\text { the investigated emulsion, } \%\end{array}$} \\
\hline & & 0.5 & 1 & 10 & 20 \\
\hline \multicolumn{6}{|c|}{ The first phase of imbibition process } \\
\hline $0.05 \%$ & $\begin{array}{l}a_{1} \\
b_{1}\end{array}$ & $\begin{array}{c}1.183 \\
\pm 0.054 \\
1.213 \\
\pm 0.033\end{array}$ & $\begin{array}{c}1.500 \\
\pm 0.135 \\
1.358 \\
\pm 0.088\end{array}$ & $\begin{array}{c}0.380 \\
\pm 0.010 \\
0.902 \\
\pm 0.009\end{array}$ & $\begin{array}{c}0.241 \\
\pm 0.005 \\
0.951 \\
\pm 0.004\end{array}$ \\
\hline $0.1 \%$ & $\begin{array}{l}a_{1} \\
b_{1}\end{array}$ & $\begin{array}{c}0.183 \\
\pm 0.005 \\
0.150 \\
\pm 0.010\end{array}$ & $\begin{array}{c}0.168 \\
\pm 0.012 \\
0.113 \\
\pm 0.002 \\
\end{array}$ & $\begin{array}{c}0.832 \\
\pm 0.058 \\
1.048 \\
\pm 0.044\end{array}$ & $\begin{array}{c}0.380 \\
\pm 0.007 \\
0.987 \\
\pm 0.005\end{array}$ \\
\hline \multicolumn{6}{|c|}{ The second phase of imbibition process } \\
\hline $0.05 \%$ & $\begin{array}{l}a_{1} \\
b_{1}\end{array}$ & $\begin{array}{c}1.638 \\
\pm 0.069 \\
1.538 \\
\pm 0.035\end{array}$ & $\begin{array}{c}3.579 \\
\pm 0.523 \\
2.517 \\
\pm 0.277\end{array}$ & $\begin{array}{c}0.719 \\
\pm 0.021 \\
1.137 \\
\pm 0.010\end{array}$ & $\begin{array}{c}0.367 \\
\pm 0.017 \\
1.025 \\
\pm 0.006\end{array}$ \\
\hline $0.1 \%$ & $\begin{array}{l}a_{1} \\
b_{1}\end{array}$ & $\begin{array}{c}2.099 \\
\pm 0.427 \\
1.844 \\
\pm 0.235\end{array}$ & $\begin{array}{c}1.756 \\
\pm 0.145 \\
1.624 \\
\pm 0.077\end{array}$ & $\begin{array}{c}0.943 \\
\pm 0.038 \\
1.220 \\
\pm 0.019\end{array}$ & $\begin{array}{c}0.505 \\
\pm 0.022 \\
1.055 \\
\pm 0.009\end{array}$ \\
\hline \multicolumn{6}{|c|}{ Entire imbibition process } \\
\hline $0.05 \%$ & $\begin{array}{l}a_{1} \\
b_{1}\end{array}$ & $\begin{array}{c}1.776 \\
\pm 0.047 \\
1.606 \\
\pm 0.025\end{array}$ & $\begin{array}{c}2.615 \\
\pm 0.134 \\
2.022 \\
\pm 0.072\end{array}$ & $\begin{array}{c}0.632 \\
\pm 0.012 \\
1.100 \\
\pm 0.006\end{array}$ & $\begin{array}{c}0.328 \\
\pm 0.006 \\
1.015 \\
\pm 0.002\end{array}$ \\
\hline $0.1 \%$ & $\begin{array}{l}a_{1} \\
b_{1}\end{array}$ & $\begin{array}{c}12.258 \\
\pm 5.882 \\
7.514 \\
\pm 3.333\end{array}$ & $\begin{array}{c}14.071 \\
\pm 8.057 \\
8.329 \\
\pm 4.451\end{array}$ & $\begin{array}{c}1.054 \\
\pm 0.031 \\
1.273 \\
\pm 0.016\end{array}$ & $\begin{array}{c}0.464 \\
\pm 0.007 \\
1.041 \\
\pm 0.003\end{array}$ \\
\hline
\end{tabular}

$3.753 \pm 0.064$ correspondingly. In the case of the oil phase concentration increasing to $20 \%$, the mentioned parameters of the modified Washburn equation also enlarge (viz. $a$ is $4.779 \pm 0.060$ and $b$ is $4.768 \pm 0.070$ ). An analogous tendency is observed for emulsions with the same higher value of the disperse phase concentration and gelatin content of $0.1 \%$ (see Table 3 ).

The parameters of the Hill equation are within the defined ranges. Thus in both cases of the separated phases, $V_{\max }$ lies in a range from 1.121 to 1.836 , while $k$ is equal to $0.214 \div 0.791$ (see Table 4).

However the coefficient $n$ is in a range of $0.433 \div 0.839$ for the first phase of the process and for the second one with gelatin concentration of $0.05 \%$. On condition of the second phase and gelatin concentration of $0.1 \%$, a value of the parameter $n$ increases and is in a range from 1.203 to 1.969 .

The divergent situation is observed for the entire process, in this case $V_{\text {max }}$ is larger and lies inside the
Table 3. Parameters for the modified Washburn equation

\begin{tabular}{|c|c|c|c|c|c|}
\hline \multirow{2}{*}{ 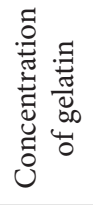 } & \multirow{2}{*}{ 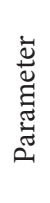 } & \multicolumn{4}{|c|}{$\begin{array}{l}\text { Concentration of the dispersed phase } \\
\text { in the investigated emulsion, } \%\end{array}$} \\
\hline & & 0.5 & 1 & 10 & 20 \\
\hline \multicolumn{6}{|c|}{ The first phase of imbibition process } \\
\hline \multirow{2}{*}{$0.05 \%$} & $a_{2}$ & $\begin{array}{c}4.089 \\
\pm 0.073\end{array}$ & $\begin{array}{c}3.814 \\
\pm 0.060\end{array}$ & $\begin{array}{c}8.777 \\
\pm 0.378\end{array}$ & $\begin{array}{l}13.330 \\
\pm 0.774\end{array}$ \\
\hline & $b_{2}$ & $\begin{array}{c}5.982 \\
\pm 0.144 \\
\end{array}$ & $\begin{array}{c}6.427 \\
\pm 0.150 \\
\end{array}$ & $\begin{array}{r}12.821 \\
\pm 0.635 \\
\end{array}$ & $\begin{array}{r}16.155 \\
\pm 1.015 \\
\end{array}$ \\
\hline \multirow[t]{2}{*}{$0.1 \%$} & $a_{2}$ & $\begin{array}{c}2.940 \\
\pm 0.035\end{array}$ & $\begin{array}{c}2.642 \\
\pm 0.034\end{array}$ & $\begin{array}{c}5.237 \\
\pm 0.170\end{array}$ & $\begin{array}{c}8.419 \\
\pm 0.382\end{array}$ \\
\hline & $b_{2}$ & $\begin{array}{c}4.429 \\
\pm 0.088\end{array}$ & $\begin{array}{c}3.895 \\
\pm 0.086\end{array}$ & $\begin{array}{c}8.982 \\
\pm 0.369\end{array}$ & $\begin{array}{l}10.103 \\
\pm 0.516\end{array}$ \\
\hline \multicolumn{6}{|c|}{ The second phase of imbibition process } \\
\hline \multirow{2}{*}{$0.05 \%$} & $a_{2}$ & $\begin{array}{c}2.889 \\
\pm 0.023\end{array}$ & $\begin{array}{c}2.844 \\
\pm 0.030\end{array}$ & $\begin{array}{c}3.772 \\
\pm 0.049\end{array}$ & $\begin{array}{r}4.779 \\
\pm 0.060\end{array}$ \\
\hline & $b_{2}$ & $\begin{array}{c}2.693 \\
\pm 0.038\end{array}$ & $\begin{array}{c}2.601 \\
\pm 0.051\end{array}$ & $\begin{array}{c}3.753 \\
\pm 0.064\end{array}$ & $\begin{array}{c}4.768 \\
\pm 0.070\end{array}$ \\
\hline \multirow[t]{2}{*}{$0.1 \%$} & $a_{2}$ & $\begin{array}{c}2.983 \\
\pm 0.024\end{array}$ & $\begin{array}{c}2.972 \\
\pm 0.011\end{array}$ & $\begin{array}{c}3.488 \\
\pm 0.023\end{array}$ & $\begin{array}{c}4.105 \\
\pm 0.088\end{array}$ \\
\hline & $b_{2}$ & $\begin{array}{c}2.671 \\
\pm 0.042\end{array}$ & $\begin{array}{c}2.749 \\
\pm 0.018\end{array}$ & $\begin{array}{c}3.475 \\
\pm 0.032\end{array}$ & $\begin{array}{c}4.110 \\
\pm 0.105\end{array}$ \\
\hline \multicolumn{6}{|c|}{ Entire imbibition process } \\
\hline \multirow{2}{*}{$0.05 \%$} & $a_{2}$ & $\begin{array}{c}3.924 \\
\pm 0.092\end{array}$ & $\begin{array}{c}3.627 \\
\pm 0.096\end{array}$ & $\begin{array}{c}6.631 \\
\pm 0.254\end{array}$ & $\begin{array}{l}11.268 \\
\pm 0.598\end{array}$ \\
\hline & $b_{2}$ & $\begin{array}{c}4.299 \\
\pm 0.121 \\
\end{array}$ & $\begin{array}{c}4.161 \\
\pm 0.141 \\
\end{array}$ & $\begin{array}{c}7.485 \\
\pm 0.322 \\
\end{array}$ & $\begin{array}{r}12.571 \\
\pm 0.719 \\
\end{array}$ \\
\hline \multirow[t]{2}{*}{$0.1 \%$} & $a_{2}$ & $\begin{array}{c}3.263 \\
\pm 0.046\end{array}$ & $\begin{array}{c}3.104 \\
\pm 0.032\end{array}$ & $\begin{array}{c}4.347 \\
\pm 0.116\end{array}$ & $\begin{array}{c}7.724 \\
\pm 0.308\end{array}$ \\
\hline & $b_{2}$ & $\begin{array}{c}3.203 \\
\pm 0.062\end{array}$ & $\begin{array}{c}3.012 \\
\pm 0.044\end{array}$ & $\begin{array}{c}4.723 \\
\pm 0.150\end{array}$ & $\begin{array}{c}8.543 \\
\pm 0.370\end{array}$ \\
\hline
\end{tabular}

boundaries of $2.012 \div 2.481$, the coefficient $k$ is founded within an interval of $0.952 \div 1.959$ and $n$ is equal to $0.412 \div 0.781$. Nevertheless, in cases of the second phase and the entire process (gelatin concentration of $0.05 \%$ and $0.1 \%$, the dispersed phase concentration of $20 \%$ ) the determined coefficients of the Hill equation are distinguished and do not follow defined tendency (see Table 4).

The correlation coefficient is applied as one of the quality criteria for the equations fitting the experimental data. It is necessary to underline the relationship between two sets of variables. The values of the correlation coefficient are given in Table 5 .

According to the results, the correlation coefficients of the modified Washburn equation are the highest for the second phase, nevertheless these values are defined as insufficient and quite low in comparison with coefficient values obtained using the Hill equation and the classical Washburn equation, besides an occurence with gelatin concentration of $0.1 \%$. 
Conforming to the results, a majority of the lowest correlation coefficient values were observed for emulsions with the dispersed phase concentration of $20 \%$, thus in this case a perfect fit to these experimental data is not obtained.

An approximation with the Hill equation provides in general the highest values of the correlation coefficient. As a result, in this case the most appropriate degree of correlation between experimental and analytical data was assumed (see Table 5).

Table 4. Parameters for the Hill equation

\begin{tabular}{|c|c|c|c|c|c|}
\hline \multirow{2}{*}{ 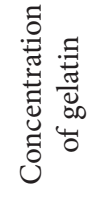 } & \multirow{2}{*}{ 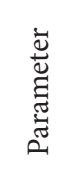 } & \multicolumn{4}{|c|}{$\begin{array}{c}\text { Concentration of the dispersed phase in } \\
\text { the investigated emulsion, } \%\end{array}$} \\
\hline & & 0.5 & 1 & 10 & 20 \\
\hline \multicolumn{6}{|c|}{ The first phase of imbibition process } \\
\hline \multirow{3}{*}{$0.05 \%$} & $V_{\max }$ & $\begin{array}{c}1.153 \\
\pm 0.049\end{array}$ & $\begin{array}{c}1.141 \\
\pm 0.067\end{array}$ & $\begin{array}{c}1.438 \\
\pm 0.108\end{array}$ & $\begin{array}{r}1.565 \\
\pm 0.102\end{array}$ \\
\hline & $k$ & $\begin{array}{c}0.236 \\
\pm 0.027\end{array}$ & $\begin{array}{c}0.257 \\
\pm 0.040\end{array}$ & $\begin{array}{c}0.283 \\
\pm 0.085\end{array}$ & $\begin{array}{r}0.214 \\
\pm 0.066\end{array}$ \\
\hline & $n$ & $\begin{array}{c}0.745 \\
\pm 0.023 \\
\end{array}$ & $\begin{array}{c}0.728 \\
\pm 0.024 \\
\end{array}$ & $\begin{array}{c}0.491 \\
\pm 0.023 \\
\end{array}$ & $\begin{array}{r}0.433 \\
\pm 0.023 \\
\end{array}$ \\
\hline \multirow{3}{*}{$0.1 \%$} & $V_{\max }$ & $\begin{array}{c}1.482 \\
\pm 0.133\end{array}$ & $\begin{array}{c}1.279 \\
\pm 0.141\end{array}$ & $\begin{array}{c}1.277 \\
\pm 0.163\end{array}$ & $\begin{array}{r}1.521 \\
\pm 0.160\end{array}$ \\
\hline & $k$ & $\begin{array}{c}0.544 \\
\pm 0.116\end{array}$ & $\begin{array}{c}0.417 \\
\pm 0.102\end{array}$ & $\begin{array}{c}0.308 \\
\pm 0.126\end{array}$ & $\begin{array}{r}0.269 \\
\pm 0.114\end{array}$ \\
\hline & $n$ & $\begin{array}{c}0.751 \\
\pm 0.026 \\
\end{array}$ & $\begin{array}{r}0.839 \\
\pm 0.037 \\
\end{array}$ & $\begin{array}{c}0.590 \\
\pm 0.039 \\
\end{array}$ & $\begin{array}{r}0.508 \\
\pm 0.042 \\
\end{array}$ \\
\hline \multicolumn{6}{|c|}{ The second phase of imbibition process } \\
\hline \multirow{3}{*}{$0.05 \%$} & $V_{\max }$ & $\begin{array}{c}1.603 \\
\pm 0.268 \\
\end{array}$ & $\begin{array}{c}1.836 \\
\pm 0.532 \\
\end{array}$ & $\begin{array}{c}1.750 \\
\pm 0.370 \\
\end{array}$ & $\begin{array}{r}1.017 \\
\pm 0.011 \\
\end{array}$ \\
\hline & $k$ & $\begin{array}{c}0.540 \\
\pm 0.024 \\
\end{array}$ & $\begin{array}{c}0.791 \\
\pm 0.068 \\
\end{array}$ & $\begin{array}{c}0.567 \\
\pm 0.048 \\
\end{array}$ & $\begin{array}{r}0.206 \\
\pm 0.026 \\
\end{array}$ \\
\hline & $n$ & $\begin{array}{c}0.792 \\
\pm 0.158\end{array}$ & $\begin{array}{c}0.789 \\
\pm 0.147\end{array}$ & $\begin{array}{c}0.501 \\
\pm 0.113\end{array}$ & $\begin{array}{r}2.418 \\
\pm 0.444\end{array}$ \\
\hline \multirow{3}{*}{$0.1 \%$} & $V_{\max }$ & $\begin{array}{c}1.121 \\
\pm 0.020 \\
\end{array}$ & $\begin{array}{c}1.178 \\
\pm 0.021 \\
\end{array}$ & $\begin{array}{c}1.161 \\
\pm 0.026 \\
\end{array}$ & $\begin{array}{r}1.608 \\
\pm 0.205 \\
\end{array}$ \\
\hline & $k$ & $\begin{array}{c}0.330 \\
\pm 0.004\end{array}$ & $\begin{array}{c}0.319 \\
\pm 0.005\end{array}$ & $\begin{array}{c}0.240 \\
\pm 0.006\end{array}$ & $\begin{array}{c}0.262 \\
\pm 0.008\end{array}$ \\
\hline & $n$ & $\begin{array}{c}1.969 \\
\pm 0.167\end{array}$ & $\begin{array}{c}1.489 \\
\pm 0.073\end{array}$ & $\begin{array}{c}1.203 \\
\pm 0.075\end{array}$ & $\begin{array}{r}0.350 \\
\pm 0.065 \\
\end{array}$ \\
\hline \multicolumn{6}{|c|}{ Entire imbibition process } \\
\hline \multirow{3}{*}{$0.05 \%$} & $V_{\text {max }}$ & $\begin{array}{c}2.377 \\
\pm 0.181 \\
\end{array}$ & $\begin{array}{c}2.200 \\
\pm 0.190 \\
\end{array}$ & $\begin{array}{c}2.214 \\
\pm 0.125 \\
\end{array}$ & $\begin{array}{r}1.358 \\
\pm 0.030 \\
\end{array}$ \\
\hline & $k$ & $\begin{array}{c}1.812 \\
\pm 0.437\end{array}$ & $\begin{array}{c}1.477 \\
\pm 0.396\end{array}$ & $\begin{array}{c}1.610 \\
\pm 0.409\end{array}$ & $\begin{array}{r}0.113 \\
\pm 0.011\end{array}$ \\
\hline & $n$ & $\begin{array}{c}0.562 \\
\pm 0.016\end{array}$ & $\begin{array}{c}0.591 \\
\pm 0.019\end{array}$ & $\begin{array}{c}0.412 \\
\pm 0.011\end{array}$ & $\begin{array}{r}0.486 \\
\pm 0.014\end{array}$ \\
\hline \multirow{3}{*}{$0.1 \%$} & $V_{\max }$ & $\begin{array}{c}2.481 \\
\pm 0.200\end{array}$ & $\begin{array}{c}2.012 \\
\pm 0.100\end{array}$ & $\begin{array}{c}2.432 \\
\pm 0.235\end{array}$ & $\begin{array}{r}1.458 \\
\pm 0.073\end{array}$ \\
\hline & $k$ & $\begin{array}{r}1.615 \\
\pm 0.333 \\
\end{array}$ & $\begin{array}{c}0.952 \\
\pm 0.115 \\
\end{array}$ & $\begin{array}{r}1.959 \\
\pm 0.687 \\
\end{array}$ & $\begin{array}{r}0.227 \\
\pm 0.046 \\
\end{array}$ \\
\hline & $n$ & $\begin{array}{c}0.688 \\
\pm 0.020\end{array}$ & $\begin{array}{c}0.781 \\
\pm 0.018\end{array}$ & $\begin{array}{c}0.518 \\
\pm 0.180\end{array}$ & $\begin{array}{r}0.525 \\
\pm 0.027 \\
\end{array}$ \\
\hline
\end{tabular}

Accuracy of the equations fitting was estimated in addition using the normalized root mean square error (NRMSE). It is a non-dimensional form of the root mean square error that is used to assess the difference between actually observed data and predicted by a certain model. The values of the normalized root mean square error are represented in Table 6.

Table 5. The correlation coefficient values for applied equations

\begin{tabular}{|c|c|c|c|c|c|c|}
\hline \multirow{2}{*}{$\begin{array}{c}\text { DPC, } \\
\% \\
\end{array}$} & \multicolumn{6}{|c|}{ Concentration of gelatin } \\
\hline & \multicolumn{3}{|c|}{$0.05 \%$} & \multicolumn{3}{|c|}{$0.1 \%$} \\
\hline \multicolumn{7}{|c|}{ The first phase of imbibition process } \\
\hline 0.5 & 0.970 & 0.995 & 0.995 & 0.985 & 0.996 & 0.845 \\
\hline 1 & 0.979 & 0.997 & 0.994 & 0.983 & 0.994 & 0.906 \\
\hline 10 & 0.877 & 0.997 & 0.993 & 0.938 & 0.990 & 0.991 \\
\hline 20 & 0.811 & 0.994 & 0.993 & 0.859 & 0.979 & 0.996 \\
\hline \multicolumn{7}{|c|}{ The second phase of imbibition process } \\
\hline 0.5 & 0.983 & 0.994 & 0.994 & 0.982 & 0.990 & 0.943 \\
\hline 1 & 0.978 & 0.988 & 0.990 & 0.997 & 0.997 & 0.984 \\
\hline 10 & 0.963 & 0.993 & 0.989 & 0.991 & 0.995 & 0.988 \\
\hline 20 & 0.972 & 0.970 & 0.942 & 0.896 & 0.950 & 0.934 \\
\hline \multicolumn{7}{|c|}{ Entire imbibition process } \\
\hline 0.5 & 0.947 & 0.996 & 0.998 & 0.979 & 0.996 & 0.989 \\
\hline 1 & 0.922 & 0.994 & 0.996 & 0.989 & 0.997 & 0.988 \\
\hline 10 & 0.840 & 0.997 & 0.994 & 0.925 & 0.995 & 0.995 \\
\hline 20 & 0.782 & 0.995 & 0.985 & 0.867 & 0.987 & 0.993 \\
\hline 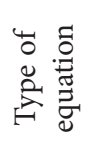 & 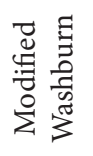 & 春 & 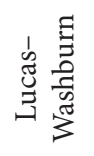 & 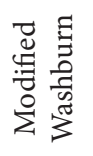 & 浔 & 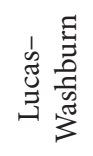 \\
\hline
\end{tabular}

Table 6. The values of the normalized root mean square error for applied equations

\begin{tabular}{|c|c|c|c|c|c|c|}
\hline \multirow{2}{*}{$\begin{array}{c}\mathrm{DPC}, \\
\%\end{array}$} & \multicolumn{6}{|c|}{ Concentration of gelatin } \\
\hline & \multicolumn{3}{|c|}{$0.05 \%$} & \multicolumn{3}{|c|}{$0.1 \%$} \\
\hline \multicolumn{7}{|c|}{ The first phase of imbibition process } \\
\hline 0.5 & 4.3 & 1.7 & 1.9 & 3.1 & 1.6 & 2.0 \\
\hline 1 & 3.8 & 1.5 & 2.1 & 3.4 & 2.2 & - \\
\hline 10 & 7.6 & 1.7 & 2.2 & 5.8 & 2.3 & 2.6 \\
\hline 20 & 9.4 & 1.6 & 2.3 & 11.4 & 2.5 & 1.9 \\
\hline \multicolumn{7}{|c|}{ The second phase of imbibition process } \\
\hline 0.5 & 3.8 & 2.4 & 2.3 & 4.1 & 3.2 & 7.2 \\
\hline 1 & 5.1 & 3.9 & 3.4 & 1.7 & 1.6 & 3.8 \\
\hline 10 & 5.7 & 2.5 & 3.3 & 2.8 & 2.1 & 3.4 \\
\hline 20 & 5.9 & 5.9 & 7.8 & 9.6 & 6.5 & 7.6 \\
\hline \multicolumn{7}{|c|}{ Entire imbibition process } \\
\hline 0.5 & 6.2 & 1.6 & 1.3 & 4.2 & 1.8 & 3.1 \\
\hline 1 & 6.6 & 1.8 & 1.6 & 3.1 & 1.6 & 3.2 \\
\hline 10 & 9.3 & 1.2 & 2.2 & 6.9 & 1.8 & 2.0 \\
\hline 20 & 9.7 & 1.4 & 3.2 & 10.3 & 2.0 & 2.2 \\
\hline 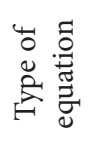 & 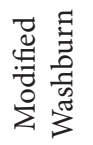 & 夆 & 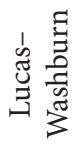 & 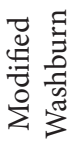 & 㳝 & 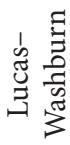 \\
\hline
\end{tabular}


Correlations between experimental data and those calculated analytically with the Washburn equation (see Eq. 1) are represented in Figures 2-4. The straight lines in the figures refer to the bounds within which solutions are found. The results are in a range of $\pm 10 \%$ for the separated first and the second phases of the imbibition process and $\pm 15 \%$ for the entire process.

From analysis of the graphs, it is possible to notice overlapping of the time intervals that can be explained by a difference in the transition points. This also depends on the disperse phase concentrations in the emulsions.

Figures 5-8 display the relation between experimental values and data received due to fitting by means of the modified Washburn equation (see Eq. 4), which is used to define the kinetics of the imbibed mass change per certain period of time.

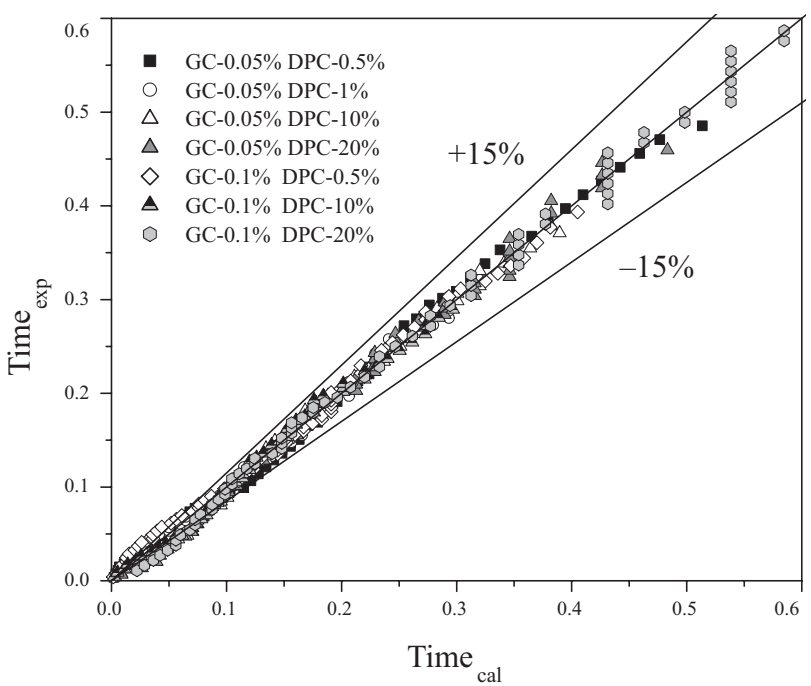

Fig. 2. Correlation between experimental values (timeexp) and calculated (timecal) by means of the classical Lucas-Washburn equation for the first phase of the imbibition process

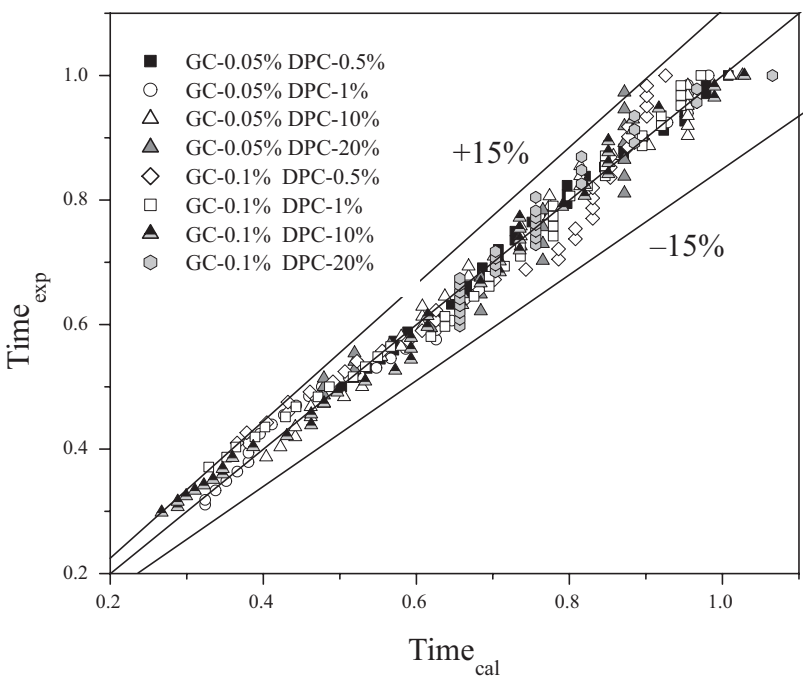

Fig. 3. Correlation between experimental values (timeexp) and calculated (timecal) by means of the classical Lucas-Washburn equation for the second phase of the imbibition process

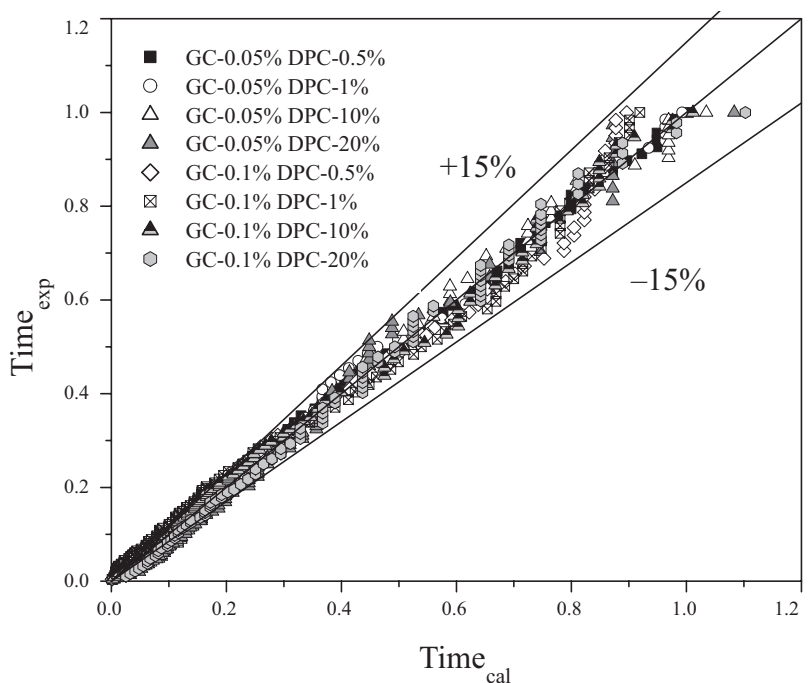

Fig. 4. Correlation between experimental values (timeexp) and calculated (timecal) by means of the classical Lucas-Washburn equation for the entire process of the imbibition process

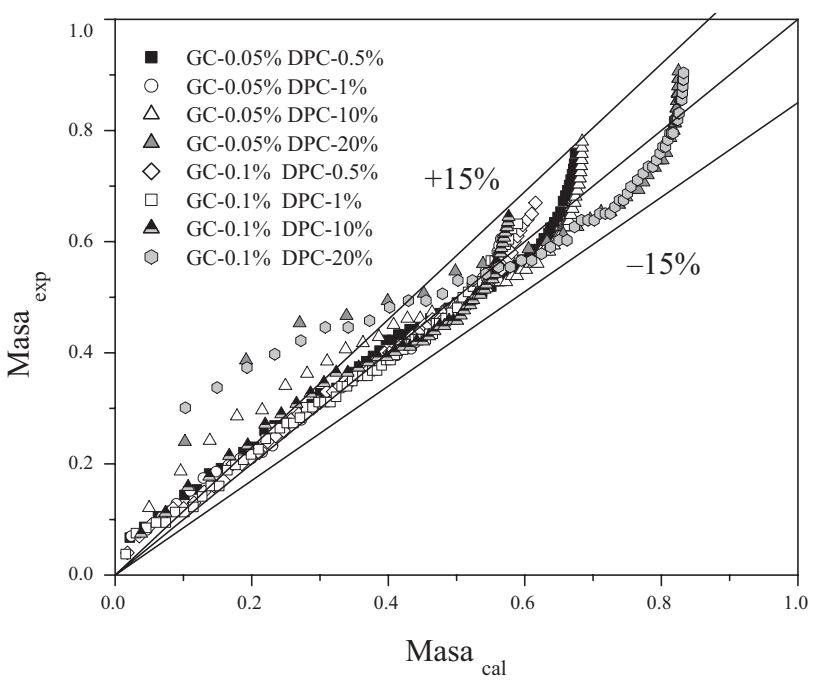

Fig. 5. Correlation between experimental values (massexp) and calculated (masscal) by means of the modified Washburn equation for the first phase of the imbibition process

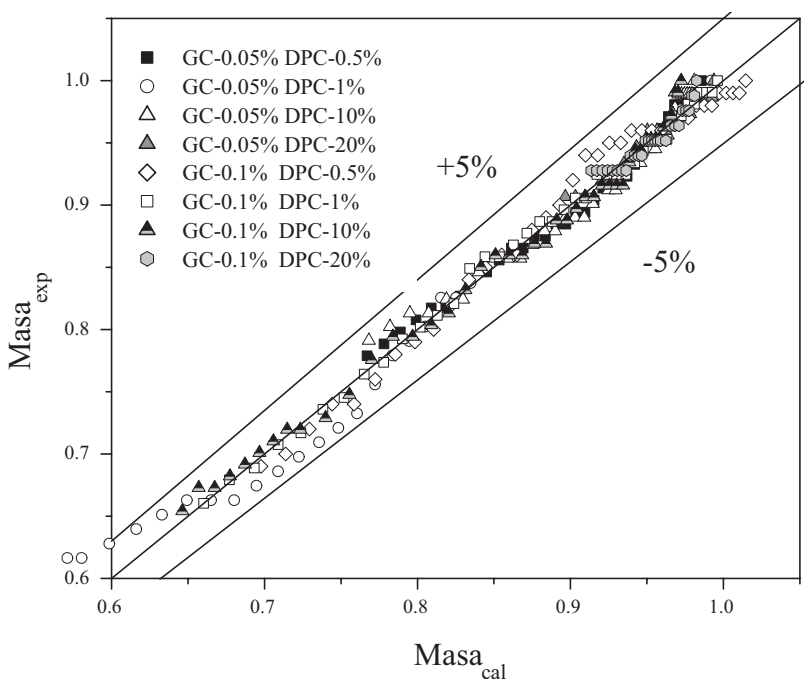

Fig. 6. Correlation between experimental values (massexp) and calculated (masscal) by means of the modified Washburn equation for the second phase of the imbibition process 


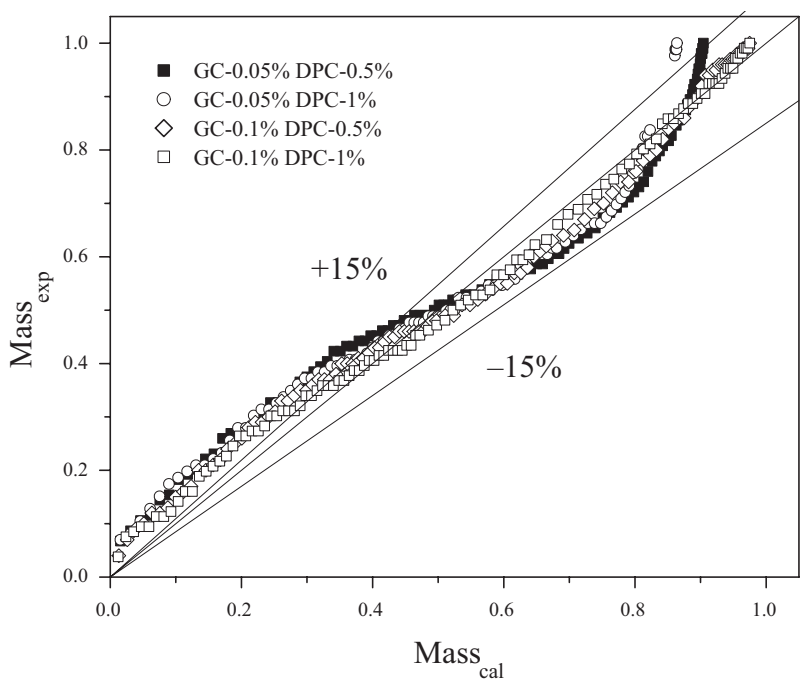

Fig. 7. Correlation between experimental values (massexp) and calculated (masscal) by means of the modified Washburn equation (entire process with gelatin content of $0.5 \%$ and $1 \%$ )

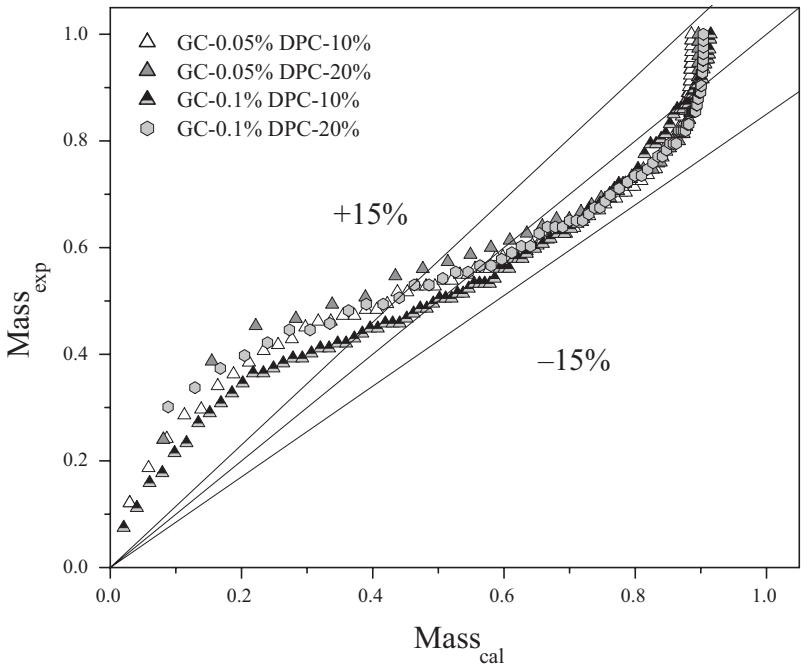

Fig. 8. Correlation between experimental values (massexp) and calculated (masscal) by means of the modified Washburn equation (entire process with gelatin content of $10 \%$ and $20 \%$ )

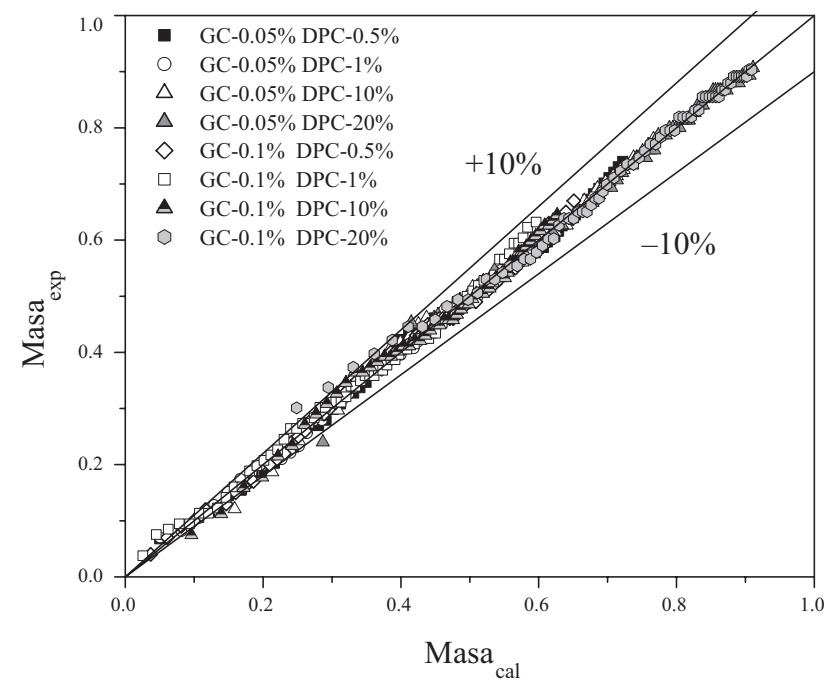

Fig. 9. Correlation between experimental values (massexp) and calculated (masscal) by means of the Hill equation for the first phase of the imbibition process
Thus, the values conditionally lie in a range of $\pm 15 \%$ for the first phases of the imbibition process, while emulsions with the dispersed phase concentration of $20 \%$ (gelatin concentrations of $0.1 \%$ and $0.05 \%$ ) and $10 \%$ (with emulsifier concentration of $0.05 \%$ ) are not in the defined range (see Fig. 5).

The values obtained for the second phases of the imbibition process are in a range of $\pm 5 \%$ (see Fig. 6).

In case of the entire process fitting by means of the modified Washburn equation, the obtained data were distributed into two sets: the first one for emulsions with the higher disperse phase concentrations (10\% and 20\%) and the second with low $(0.05-1 \%)$. The main purpose of such separation was to show the specific tendencies that are representative for emulsions with the lower disperse phase concentration (see Fig. 7) and for another type of the investigated medium (see Fig. 8).

Thus, the modified Washburn equation approximates more precisely the experimental data of the entire process on condition that the disperse phase concentration of an emulsion is low and equals $0.05-1 \%$.

In detail, Figures 9-11 describe the relation between experimental values of the mass change and those calculated by means of the Hill equation.

Considering the results, one may assume that this equation gives a better approximation of the experimental data in comparison with other applied models because of lower bounds within which solutions are found. Thus, values lie within an interval of $\pm 10 \%$ for the first phase and the entire process, while in the case of the secondary phase the bounds are delineated in a range of $\pm 5 \%$.

An analysis of the porous material imbibition with oil was also conducted in order to compare with emulsions and obtained experimental data were also approximated by the referred equations. The results of fitting are represented in tabular and graphical forms.

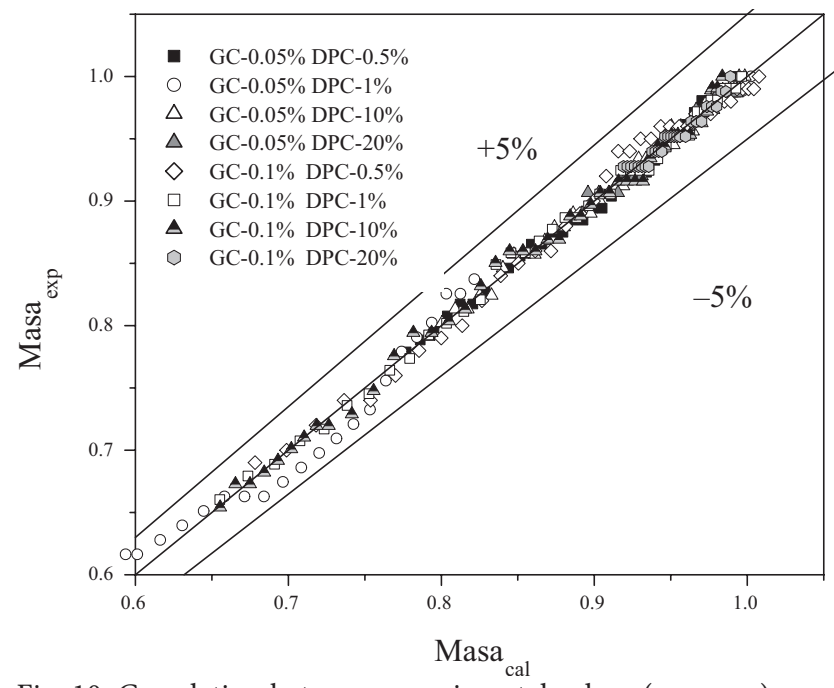

Fig. 10. Correlation between experimental values (massexp) and calculated (masscal) by means of the Hill equation for the second phase of the imbibition process 
The accuracy of the models was estimated as in the previous cases via correlation coefficient and normalized root mean square error. The values are given in Table 7 .

The values of parameters for the classical Washburn equation (see Eq. 2) in the case of sorbent imbibition with oil significantly differ from parameters obtained for emulsions. The analogous situation is observed for the modified Washburn equation (see Eq. 4).

In case of the Hill equation (see Eq. 5), the value of the parameter Vmax is slightly lower (viz. 1.091土 $0.024)$, but in spite of this it lies close to the typical interval for emulsions (see Table 4 and 7 ). The same situation is observed for the coefficient $k$. The parameter $\mathrm{n}$ is equal to $1.146 \pm 0.057$, but by contrast, it is mainly higher than in the case of material imbibition with emulsions.

According to the results, the correlation coefficient for the Hill equation is higher compared with other applied models and is equal to 0.992 (see Table 7). The value of the normalized root mean square error is also lower in case of the mentioned equation (viz. it is 2.4).

Thus it is possible to assume that generally approximation with the Hill equation provides the most appropriate and precise description of the process of the porous material imbibition with emulsions and oil.

Figures 12-14 display the relation between experimental data and results received due to fitting by means of the proposed equations. The values are in the range of $\pm 10 \%$ in case of fitting via the classical Washburn equation and its modified version (see Fig. 12 and 13) and $\pm 5 \%$ if

Table 7. Parameters of the equations applied to describe the porous material imbibition with oil

\begin{tabular}{|c|c|c|c|}
\hline $\begin{array}{l}\text { Parameter } \\
\text { of equation }\end{array}$ & $\begin{array}{l}\text { Value of } \\
\text { parameter }\end{array}$ & $\begin{array}{l}\text { Correlation } \\
\text { coefficient, } R\end{array}$ & $\begin{array}{c}\text { Normalized root } \\
\text { mean square } \\
\text { error, NRMSE }\end{array}$ \\
\hline \multicolumn{4}{|c|}{ Classical Lucas-Washburn equation } \\
\hline$a_{1}$ & $\begin{array}{c}0.717 \\
\pm 0.033 \\
\end{array}$ & & \\
\hline$b_{1}$ & $\begin{array}{c}1.121 \\
\pm 0.015\end{array}$ & 0.989 & 18.4 \\
\hline \multicolumn{4}{|c|}{ Modified Washburn equation } \\
\hline$a_{1}$ & $\begin{array}{c}4.443 \\
\pm 0.106 \\
\end{array}$ & & \\
\hline$b_{1}$ & $\begin{array}{c}4.675 \\
\pm 0.132 \\
\end{array}$ & 0.983 & 3.4 \\
\hline \multicolumn{4}{|c|}{ Hill equation } \\
\hline$V_{\max }$ & $\begin{array}{c}1.091 \\
\pm 0.024 \\
\end{array}$ & & \\
\hline$K$ & $\begin{array}{c}0.165 \\
\pm 0.008\end{array}$ & 0.992 & 2.4 \\
\hline$N$ & $\begin{array}{c}1.146 \\
\pm 0.057\end{array}$ & & \\
\hline
\end{tabular}

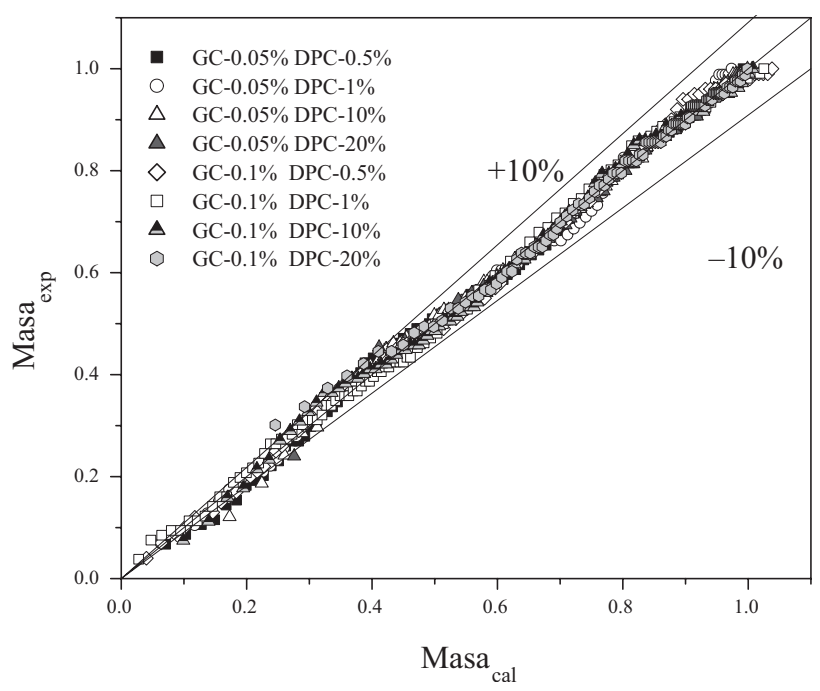

Fig. 11. Correlation between experimental values (massexp) and calculated (masscal) by means of the Hill equation for the entire process of the imbibition process

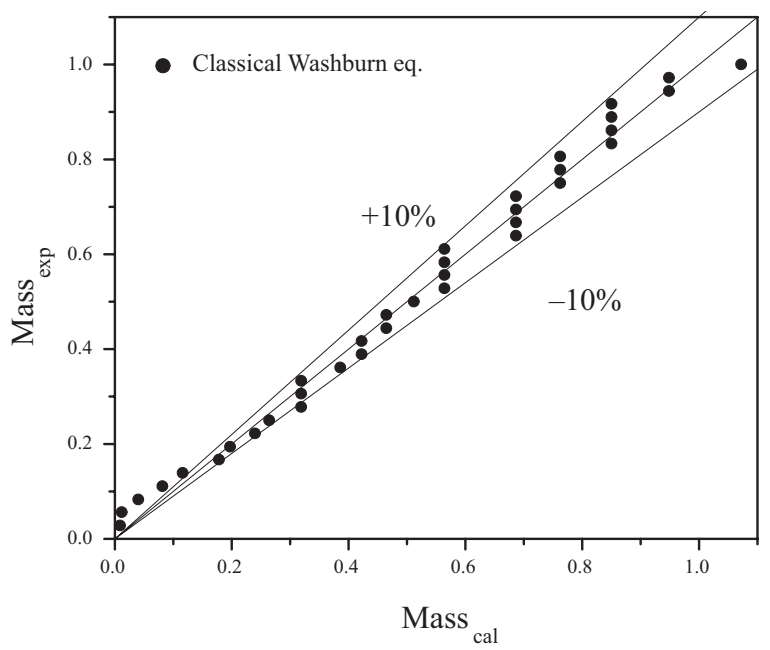

Fig. 12. Correlation between experimental values (mass exp $_{\text {) }}$ ) and calculated ( mass $_{\text {cal }}$ ) by means of the classical Lucas-Washburn equation for the process of porous material imbibition with oil

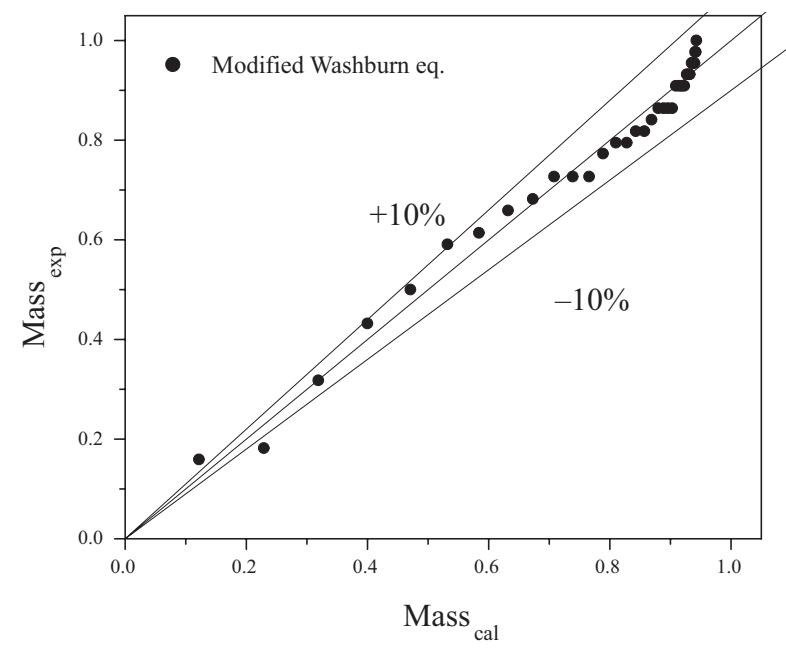

Fig. 13. Correlation between experimental values (mass exp $_{\text {) }}$ and calculated (mass cal $_{\text {) }}$ ) by means of the modified Washburn equation for the oil imbibition process 


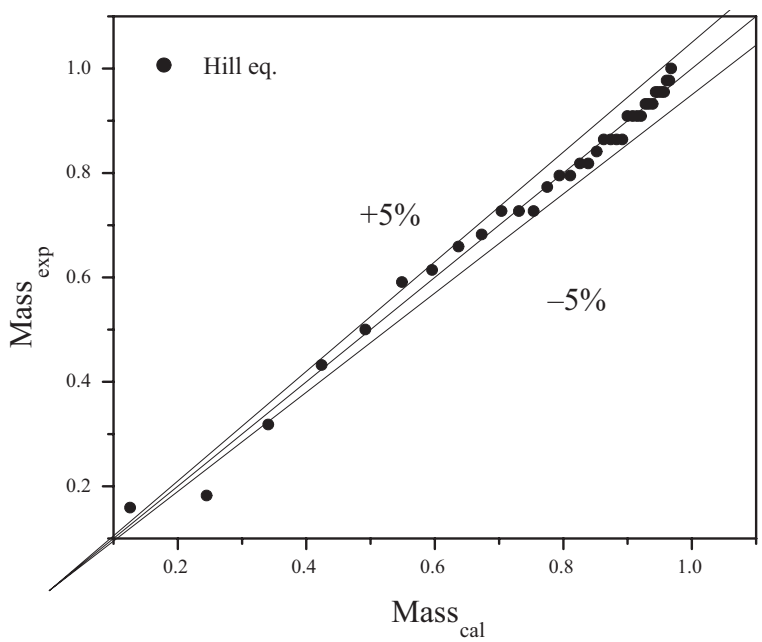

Fig. 14. Correlation between experimental values (mass exp $_{\text {) }}$ and calculated (mass cal $_{\text {) }}$ by means of the Hill equation for the oil imbibition process

description is fulfilled by means of the Hill equation (see Fig. 14).

\section{Conclusions}

1. A mathematical description of the porous material imbibition with oil and emulsions is discussed. The advanced approach of this publication lies in alteration of the classical and modified Washburn equations via substitution of commonly used parameter of the height, $h(t)$ by the parameter $m_{h}(t)$ that denotes the mass of an imbibed emulsion/oil.

2. The classical Hill equation was adapted and used to describe and predict the process of the porous material imbibition with petrochemicals for the first time.

3. The results of these investigations show that the highest correlation coefficient values for all investigated cases $\left(R_{a v}=0.995 \pm 0.001\right)$ and the lowest normalized root mean square error $\left(N R M S E_{a v} 1.95 \pm 0.138\right)$ are mostly defined in case of approximation by means of the Hill equation (exception is $20 \%$ emulsion). Moreover, the solutions of fitting via this equation lie within restricted intervals: $\pm 10 \%$ for the first phase and the entire process and $\pm 5 \%$ for the secondary phase and in case of the imbibition with oil.

4. Thus, summarizing it is possible to assume that the Hill equation provides the most appropriate and precise description of the process of the porous material imbibition with "oil-in-water" emulsions as well as with oil in comparison with other proposed equations.

\section{Reference}

Adebajo, M. O.; Frost, R. L.; Kloprogge, J. T.; Carmody, O. 2003. Porous materials for oil spill cleanup: a review of synthesis and absorbing properties, Journal of Porous Materials 10(3): 159-170. http://dx.doi.org/10.1023/A:1027484117065
Alava, M.; Dubéc, M. ; Rost, M. 2004. Imbibition in disordered media, Advances in Physics 53(2): 83-175. http://dx.doi.org/10.1080/00018730410001687363

Al-Majed, A. A.; Adebayo, A. R.; Hossain, M. E. 2012. A sustainable approach to controlling oil spills, Journal of Environmental Management 113: 213-227.

http://dx.doi.org/10.1016/j.jenvman.2012.07.034

Chan, T. Y.; Hsu, C. S.; Lin, S. T. 2004. Factors affecting the significance of gravity on the infiltration of a liquid into a porous solid, Journal of Porous Materials 11: 273-277. http://dx.doi.org/10.1023/B:JOPO.0000046354.27879.9b

Chebbi, R. 2007. Dynamics of liquid penetration into capillary tubes, Journal of Colloid and Interface Science 315(1): 255-260. http://dx.doi.org/10.1016/j.jcis.2007.06.073

Fingas, M. 2011. Oil spill science and technology: prevention, response, and clean up. Elsevier, Burlington.

Fries, N.; Dreyer, M. 2008. An analytic solution of capillary rise restrained by gravity, Journal of Colloid and Interface Science 320: 259-263. http://dx.doi.org/10.1016/j.jcis.2008.01.009

Gesztelyi, R.; Zsuga, J.; Kemeny-Beke, A.; Varga, B.; Juhasz, B.; Tosaki, A. 2012. The Hill equation and the origin of quantitative pharmacology, Archive for History of Exact Sciences 66(4): 427-438. http://dx.doi.org/10.1007/s00407-012-0098-5

Gmurman, V. E. 2004. Probability theory and mathematical statistics. 10 ed. Higher School, Moscow (in Russian).

Goutelle, S.; Maurin, M.; Rougier, F.; Barbaut, X.; Bourguignon, L.; Ducher, M.; Pascal, M. 2008. The Hill equation: a review of its capabilities in pharmacological modeling, Fundamental \& Clinical Pharmacology 22(6): 633-648. http://dx.doi.org/10.1111/j.1472-8206.2008.00633.x

Hamraoui, A.; Nylander, T. 2002. Analytical approach for the Lucas-Washburn equation, Journal of Colloid and Interface Science 250(2): 415-421. http://dx.doi.org/10.1006/jcis.2002.8288

Hilpert, M. 2010. Liquid withdrawal from capillary tubes: explicit and implicit analytical solution for constant and dynamic contact angle, Journal of Colloid and Interface Science 351(1): 267-276. http://dx.doi.org/10.1016/j.jcis.2010.07.016

Onwurah, I.; Ogugua, V.; Onyike, N.; Ochonogor, A.; Otitoju, O. 2007. Crude oil spills in the environment, effects and some innovative clean-up biotechnologies, International Journal of Environmental Research 1(4): 307-320.

Maggi, F.; Alonso-Marroquin, F. 2012. Multiphase capillary flows, International Journal of Multiphase Flow 42: 62-73. http://dx.doi.org/10.1016/j.ijmultiphaseflow.2012.01.011

Masoodi, R.; Pillai, K. M.; Varanasi, P. P. 2007. Darcy's law based models for liquid absorption in polymer wicks, AIChe Journal 53(11): 2769-2782. http://dx.doi.org/10.1002/aic.11322

Schnoor, J. L. 2010. The Gulf oil spill, Environmental Science and Technology 44(13): 4833. http://dx.doi.org/10.1021/es101727m

Siebold, A.; Nardin, M.; Schultz, J.; Walliser, A.; Oppliger, M. 2000. Effect of dynamic contact angle on capillary rise phenomena, Colloids and Surfaces A: Physicochemical and Engineering Aspects Flow 161(1): 81-87. http://dx.doi.org/10.1016/S0927-7757(99)00327-1

Shafir, S.; Van Rijn, J.; Rinkevich, B. 2007. Short and long term toxicity of crude oil and oil dispersants to two representative coral species, Environmental Science and Technology 41(15): 5571-5574. http://dx.doi.org/10.1021/es0704582 
Valentukevičienè, M.; Ignatavičius, G. 2011. Analysis and evaluation of the effect of the solids from road surface runoff on the sediments of river bed, Ekologija 57(1): 39-45. http://dx.doi.org/10.6001/ekologija.v57i1.1308

Xue, H. T; Fang, Z. N.; Yang, Y.; Huang, J. P.; Zhou, L. W. 2006. Contact angle determined by spontaneous dynamic capillary rises with hydrostatic effects: experiment and theory, Chemical Physics Letters 432(1-3): 326-330. http://dx.doi.org/10.1016/j.cplett.2006.10.017

Wei, Q. F.; Mather, R. R.; Fotheringham, A. F.; Yang, R. D. 2003. Evaluation of polypropylene nonwoven oil sorbents in marine oil spill recovery, Marine Pollution Bulletin 46(6): 780-783. http://dx.doi.org/10.1016/S0025-326X(03)00042-0

Zhmud, B. V.; Tiberg, F.; Hallstensson, K. 2000. Dynamics of capillary rise, Journal of Colloid and Interface Science 228: 263-269. http://dx.doi.org/10.1006/jcis.2000.6951

Zhu, H.; Qiu, S.; Jiang, W.; Wu, D.; Zhang, C. 2011. A evaluation of electrospun polyvinyl chloride/polystyrene fibers as sorbent materials for oil spill cleanup, Environmental Science and Technology 45(10): 4527-4531. http://dx.doi.org/10.1021/es2002343

Jerzy SEK. DSc Eng., Professor of the Department of Chemical Engineering, Faculty of Process and Environmental Engineering, Lodz University of Technology, Lodz (Poland). Publications: author/co-author of over 50 scientific papers. Research interests: emulsions, rheology, porous media, sorption.

Olga S. SHTYKA. MSc, PhD student of the Department of Chemical Engineering, Faculty of Process and Environmental Engineering, Lodz University of Technology, Lodz (Poland). Publications: author/co-author of over 20 scientific papers. Research interests: emulsions sorbtion, porous medium sorbtion, process engenering, nanomaterials.

Kamila SZYMCZAK. MSc of the Department of Chemical Engineering, Faculty of Process and Environmental Engineering, Lodz University of Technology, Lodz (Poland). Publications: author/co-author of over 5 scientific papers. Research interests: emulsion absorbtion, synthetic materials. 